\title{
Elastase and metalloproteinase-9 concentrations in saliva in patients with chronic periodontitis
}

\author{
MAEGORZATA NĘDZI-GÓRA ${ }^{l}$, JOLANTA KOSTRZEWA-JANICKA ${ }^{2}$, RENATA GÓRSKA ${ }^{l}$
}

${ }^{1}$ Department of Periodontology and Oral Mucosal Membrane Diseases, Warsaw Medical University, Warsaw, Poland

${ }^{2}$ Department of Prosthodontics, Warsaw Medical University, Warsaw, Poland

\begin{abstract}
Elastase and metalloproteinase-9 (MMP-9) are two of numerous proteolytic enzymes released by neutrophilic granulocytes in the course of periodontitis. The aim of the study was to determine the concentrations of elastase and MMP-9 in saliva in patients with chronic periodontitis compared to healthy individuals.

The enzyme-linked immunosorbent assay method was employed to determine the concentrations of elastase and MMP-9 in saliva in patients with chronic periodontitis and with pocket depth (PD) $\geq 6 \mathrm{~mm}$ and $P D<6 \mathrm{~mm}$, as well as in saliva of healthy individuals. Significantly higher concentrations of elastase and MMP-9 were observed in patients with periodontitis compared to healthy individuals $(p<0.01)$. Also a significant difference in elastase concentration in saliva was observed between the $P D \geq 4 \mathrm{~mm}$ and $P D<6 \mathrm{~mm}$ groups and between the $P D \geq 6 \mathrm{~mm}$ and control groups, and statistically significant differences in MMP-9 concentrations between the $P D \geq 6 \mathrm{~mm}$ and control groups. No statistically significant differences were observed between the $P D<6 \mathrm{~mm}$ and control groups for elastase concentrations in saliva as well as between the $P D \geq 6 \mathrm{~mm}$ and $P D<6 \mathrm{~mm}$ groups, and also between the $P D<6 \mathrm{~mm}$ and control groups for MMP-9 concentrations in saliva. Elastase and MMP-9 concentrations in saliva can be considered as biochemical indicators of severity of periodontitis.
\end{abstract}

Key words: chronic periodontitis, elastase, metalloproteinase-9.

(Centr Eur J Immunol 2014; 39 (3): 357-364)

\section{Introduction}

The traditional diagnosis of periodontal disease is based on clinical and radiological examination. Ideal diagnosis should be based not only on clinical parameters of periodontal tissues at the moment of examination, but also on clinical and biochemical indices which could indicate a potential progression of the disease. Unfortunately, until now no ideal indicators have been developed which could predict progression of the disease, primarily in patients with possible periodontal lesions at early age, or which could detect a risk of such lesions at the subclinical level. We still have at our disposal solely methods of examining the clinical attachment loss (CAL) and radiological methods of alveolar bone loss (BL) assessment. Unfortunately, observation of these indicators in time is possible only after a few millimetres of clinical attachment or bone have been lost. Therefore, for many years researchers have been trying to develop diagnostic tests which could help to identify patients (or certain sites in a patient's periodontium) particularly susceptible to occurrence and fast progress of periodontal disease [1].
Numerous studies were devoted to determining specific bacterial species (strains) present in dental plaque, which are responsible for faster progression of periodontal disease of its occurrence at an early age. Nowadays, the so-called red complex bacteria Porphyromonas gingivalis, Tannerella forsythia, Treponema denticola and green complex Aggregatibacter actinomycetemcomitans are regarded as indicator species [2-6].

Many clinical studies tried to establish various substances in gingival crevicular fluid, saliva or gingival tissue which could be indicators of disease progression. These substances include such inflammatory mediators as PGE2, interleukins e.g. IL-1 $\beta$, enzymes e.g. elastase and metalloproteinases $[7,8]$. These substances are secreted by periodontal cells (fibroblasts, keratinocytes) and inflammatory cells. In the light of contemporary studies it is known that although the primary etiological factor in chronic periodontitis is bacteria, most destructive processes within the bone and connective tissue occur after initiation of immuno-inflammatory processes within the above-mentioned tissues.

Correspondence: Małgorzata Nędzi-Góra, PhD, Department of Periodontology and Oral Mucosal Membrane Diseases, Warsaw Medical University, Miodowa 18, 00-246 Warsaw, Poland, tel./fax +48 2250220 36, e-mail: mnedzi-gora@wp.pl 
Elastase is a neutral serine proteinase (endopeptidase) "stored" in azurophilic granules of granulocytes, at the number of $3 \mathrm{pg}$ per cell. The enzyme is capable of degrading a large spectrum of various molecules in human tissues, including periodontal tissues, such as collagen, laminin, fibronectin, proteoglycans and elastin [9]. Elastase seems to play a particular role in the early stages of periodontal disease, as contrary to e.g. collagenases it can destroy intact non-collagenous proteins. In healthy periodontium these proteins surround collagen fibers protecting them against activity of collagenases [10,11].

Elastase is one of numerous proteolytic enzymes (proteases) released by neutrophilic granulocytes as a result of such phenomena as tissue destruction or bacterial infection. Elastase is present in granules of granulocytes in the form of both a proenzyme and an active enzyme, however their activating mechanisms are not fully known. Outside the cell, elastase activity control is performed mainly by serine proteinase inhibitor - alpha-1-antitrypsin (A1AT), produced and released also by neutrophils [12].

Neutrophilic granulocytes are dominant leukocytes in epithelium of periodontal pockets and adjacent periodontal tissues. They protect periodontal tissues against bacterial infections and subsequent tissue destruction by means of oxidative and non-oxidative mechanisms. The latter seem to be of the highest significance in anaerobic conditions of the periodontal pocket. Most antibacterial substances are located in azurophilic granules of neutrophilic granulocytes. They are capable of destroying phagocytized bacteria, but they can be also released extracellularly during phagocytosis [13].

Numerous in vitro studies confirmed that neutrophilic granulocytes activated by bacteria from dental plaque - release lysosomal enzymes, including elastase [14-18]. Elastase reaches one of the highest levels among proteinases marked quantitatively in gingival crevicular fluid (GCF).

Matrix metalloproteinases are a group of proteolytic enzymes, acting extracellularly. Initially, it was believed that each metalloproteinase has its own substrate. Now it is known that they can decompose a variety of extracellular matrix proteins. Substrates for metalloproteinase 9 (MMP-9) are, inter alia, type IV, V, VII, X, XIV collagen, gelatin, elastin, fibronectin, osteonectin, plasminogen. Under physiological conditions, MMP-9, as well as other metalloproteinases, is produced by connective and epithelial tissue cells, and is involved in their remodeling and healing. In the course of periodontitis, cells exposed to products released by bacteria, cytokines and growth factors, secrete higher amounts of metalloproteinases [19, 20]. Metalloproteinase 9 is also secreted by inflammatory cells. Metalloproteinases secreted by immune cells such as PMN leukocytes and monocytes/macrophages allow them to migrate from the blood vessels and to penetrate tissues, which is the essence of the processes occurring in inflammatory diseases. Excessively produced and secreted metalloproteinases destroy components of connective tissue extracellular ma- trix. Moreover, inflammatory cells stimulated by bacteria secrete cytokines which in turn stimulate stationary cells to produce metalloproteinases. Studies have shown that PMN leukocytes stimulated in vitro secrete MMP-8 and MMP9 from intracellular granules within a few seconds from commencement of stimulus action [21-23].

The gingival (periodontal) crevicular fluid, which is a transudate from serum or inflammatory transudate, is a reflection of blood serum ingredients as well as cellular response and processes occurring in marginal periodontium. Examination of gingival crevicular fluid plays an important role in scientific research on pathophysiology of periodontal disease. Cellular (e.g. granulocytes) and humoral (e.g. enzymes) elements of crevicular fluid penetrate into saliva. An analysis of GCF-originated mediators in mixed saliva could be a fast screening method for periodontal disease [24].

\section{Aim}

The aim of the study was to assess elastase and MMP-9 concentrations in saliva in patients with chronic periodontitis compared to individuals with healthy periodontium, and to determine the correlation between concentrations of the two enzymes in saliva.

\section{Material and methods}

The study included a group of 32 patients (20 females and 12 males) with diagnosed chronic periodontitis [25]. Inclusion criteria were $\geq 18$ years of age, $\geq 10$ erupted teeth, clinical attachment loss (CAL) $\geq 3 \mathrm{~mm}$. Within the group two subgroups were distinguished according to periodontal pocket occurrence: pocket depth (PD) $\geq 6 \mathrm{~mm}$ and PD $<6 \mathrm{~mm}$. Average age was 41.76 years. None of the patients reported any coexisting systemic diseases and was subject to long-term pharmacological treatment. Individuals who during the previous three months were treated with antibiotics or anti-inflammatory medications, especially non steroidal anti-inflammatory drugs and aspirin, were excluded from the study. Exclusion criteria were smoking, pregnancy, lactation, too. The control group consisted of 13 individuals (7 females and 6 males) with healthy periodontium - without clinical attachment loss, without periodontal pockets $>3 \mathrm{~mm}$ and with bleeding index $<10 \%$. Due to the above criteria, average age in the control group was 32.2 years.

Five milliliters of whole mixed expectorated saliva was collected from each individual between 9.00 and 13.00 hours (at least 2 hours after a meal) according to a modification of the method described by Navazesh [26]. Patients rinsed their mouth with tap water and expectorated whole saliva into sterile tube while seated in an upright position. The collected material was frozen at $-20^{\circ} \mathrm{C}$ and stored in that temperature until biochemical tests were performed. Samples were analyzed within 3 months of collection. 
Elastase and MMP-9 concentrations in saliva was determined in duplicate for each subject with enzyme-linked immunosorbent assay kits ELISA (R\&D Systems Minneapolis MN, USA), according to the manufacturer's directions. Standards were included on all runs and all results are reported within the linearity of the assays. The test sensitivity was $1.98 \mathrm{ng} / \mathrm{ml}$ and $0.156 \mathrm{ng} / \mathrm{ml}$, respectively.

\section{Statistical analysis}

The concentrations of elastase and MMP-9 in three groups of patients ( $\mathrm{PD} \geq 4 \mathrm{~mm}, \mathrm{PD}<4 \mathrm{~mm}$ and control) was compared. In order to determine if the differences between the groups are significant (after checking for normality of the distribution with Kolmogorov-Smirnov test), one-way analysis of variance was used. In the case of a rejection of the hypothesis about lack of differences in the level of examined parameters between groups, Tukey's multiple comparison test was used to assess differences between group pairs. Interdependence between elastase and MMP-9 concentrations was assessed with Pearson correlation coefficients. All calculations were performed with SPSS 12.0 statistical software package.

\section{Results}

The mean concentration of elastase in saliva in patients with periodontitis was $11204.44 \mathrm{ng} / \mathrm{ml}$, whereas in the control group the result was $2849.38 \mathrm{ng} / \mathrm{ml}$. Metalloproteinase 9 concentration in saliva in patients with periodon- titis was $418.97 \mathrm{ng} / \mathrm{ml}$, in the control group the result was $221.15 \mathrm{ng} / \mathrm{ml}$. The differences were statistically significant $(p<0.01$ for elastase and $p=0.025$ for MMP-9) (Table 1). After dividing the study group into two subgroups, $\mathrm{PD} \geq 6 \mathrm{~mm}$ and $\mathrm{PD}<6 \mathrm{~mm}$, the distribution of examined parameters did not significantly differ from the normal one. Variance analysis showed significant differences between examined parameters ( $p$ for variance analysis $<0.001$ ) (Table 2). In Tukey's multiple comparison test significant differences were observed in the elastase concentration in saliva between the PD $\geq 6 \mathrm{~mm}$ and PD $<6 \mathrm{~mm}$ groups as well as between PD $\geq 6 \mathrm{~mm}$ and control groups, however no statistically significant differences were observed between the $\mathrm{PD}<6 \mathrm{~mm}$ and control groups (Table 3 ). The same test disclosed significant differences between the $\mathrm{PD} \geq 6 \mathrm{~mm}$ and control groups for MMP-9. The PD $\geq 6 \mathrm{~mm}$ and groups as well as the PD $<6 \mathrm{~mm}$ and control groups did not indicate statistically significant differences (Table 3).

Moreover, a significant negative correlation was observed between age and the number of teeth in the PD $\geq 6 \mathrm{~mm}$ and $\mathrm{PD}<6 \mathrm{~mm}$ groups, and a statistically significant positive correlation between elastase and MMP-9 concentrations in the PD $\geq 6 \mathrm{~mm}$ group. No significant correlations of the above mentioned parameters were observed in the control group (Table 4).

\section{Discussion}

Cross-sectional examinations showed an increased level of elastase in diseased sites compared to healthy sites

Table 1. Comparison of elastase and MMP-9 concentrations in saliva between the whole study and control groups

\begin{tabular}{lccccc}
\hline & Group & $\boldsymbol{N}$ & Mean & SD & $\boldsymbol{p}$ \\
\hline \multirow{2}{*}{ Elastase } & control & 13 & 2849.38 & 2418.146 & $<0.001$ \\
\cline { 2 - 5 } & study & 32 & 11204.44 & 9365.738 & \\
\hline \multirow{2}{*}{ MMP-9 } & control & 13 & 221.15 & 156.607 & 0.025 \\
\cline { 2 - 5 } & study & 32 & 418.97 & 414.582 & \\
\hline
\end{tabular}

Table 2. Comparison of elastase and MMP-9 concentrations in saliva between PD $\geq 6 \mathrm{~mm}$, PD $<6 \mathrm{~mm}$ and control groups

\begin{tabular}{|c|c|c|c|c|c|c|c|}
\hline & & $N$ & Mean [ng/ml] & SD & $\operatorname{Min}[\mathrm{ng} / \mathrm{ml}]$ & Max [ng/ml] & $p_{\text {ANOVA }}$ \\
\hline \multirow[t]{3}{*}{ Elastase } & $\mathrm{PD} \geq 6 \mathrm{~mm}$ & 16 & 17870.1 & 8804.2 & 5500 & 37000 & $<0.001 *$ \\
\hline & $\mathrm{PD}<6 \mathrm{~mm}$ & 16 & 4538.8 & 2996.9 & 320 & 9700 & \\
\hline & control & 13 & 2849.4 & 2418.1 & 330 & 6500 & \\
\hline \multirow[t]{3}{*}{ MМР-9 } & $\mathrm{PD} \geq 6 \mathrm{~mm}$ & 16 & 565.8 & 493.6 & 32 & 1710 & $0.017 * *$ \\
\hline & $\mathrm{PD}<6 \mathrm{~mm}$ & 16 & 272.2 & 256.1 & 60 & 953 & \\
\hline & control & 13 & 221.2 & 156.6 & 15 & 535 & \\
\hline
\end{tabular}

*In Tukey's multiple comparison test, significant differences were observed between $P D \geq 6 \mathrm{~mm}$ and PD $<6 \mathrm{~mm}$ groups as well as between PD $\geq 4$ mm and control groups, no statistically significant differences were observed between $P D<6 \mathrm{~mm}$ and control groups

**In Tukey's multiple comparison test, significant differences were observed between $P D \geq 6 \mathrm{~mm}$ and control groups. The PD $\geq 6 \mathrm{~mm}$ and PD $<6 \mathrm{~mm}$ groups as well as $P D<6 \mathrm{~mm}$ and control groups, do not indicate statistically significant differences 
Table 3. Tukey's test results. Multiple comparisons of elastase and MMP-9 concentrations in saliva between $\mathrm{PD} \geq 6 \mathrm{~mm}, \mathrm{PD}<6 \mathrm{~mm}$ and control groups

\begin{tabular}{|c|c|c|c|c|c|c|c|}
\hline \multirow{2}{*}{$\begin{array}{l}\text { Dependent } \\
\text { variable }\end{array}$} & \multirow[t]{2}{*}{ (I) Group 1} & \multirow[t]{2}{*}{ (J) Group 1} & \multirow{2}{*}{$\begin{array}{l}\text { Mean difference } \\
\text { (I-J) }[\mathrm{ng} / \mathrm{ml}]\end{array}$} & \multirow[t]{2}{*}{ Standard error } & \multirow[t]{2}{*}{ Significance } & \multicolumn{2}{|c|}{ 95\% Confidence Interval } \\
\hline & & & & & & lower limit & upper limit \\
\hline \multirow[t]{6}{*}{ elastase } & $\mathrm{PD} \geq 6 \mathrm{~mm}$ & $\mathrm{PD}<6 \mathrm{~mm}$ & $13331.375(*)$ & 2017.478 & .000 & 8429.92 & 18232.83 \\
\hline & & control & $15020.740(*)$ & 2130.694 & .000 & 9844.23 & 20197.25 \\
\hline & $\mathrm{PD}<6 \mathrm{~mm}$ & $\mathrm{PD} \geq 6 \mathrm{~mm}$ & $-13331.375(*)$ & 2017.478 & .000 & -18232.83 & -8429.92 \\
\hline & & control & 1689.365 & 2130.694 & .709 & -3487.14 & 6865.87 \\
\hline & control & $\mathrm{PD} \geq 6 \mathrm{~mm}$ & $-15020.740(*)$ & 2130.694 & .000 & -20197.25 & -9844.23 \\
\hline & & $\mathrm{PD}<6 \mathrm{~mm}$ & -1689.365 & 2130.694 & .709 & -6865.87 & 3487.14 \\
\hline \multirow[t]{6}{*}{ MMP-9 } & $\mathrm{PD} \geq 6 \mathrm{~mm}$ & $\mathrm{PD}<6 \mathrm{~mm}$ & 293.556 & 121.169 & .051 & -.82 & 587.94 \\
\hline & & control & $344.596(*)$ & 127.969 & .027 & 33.70 & 655.50 \\
\hline & $\mathrm{PD}<6 \mathrm{~mm}$ & $\mathrm{PD} \geq 6 \mathrm{~mm}$ & -293.556 & 121.169 & .051 & -587.94 & .82 \\
\hline & & control & 51.040 & 127.969 & .916 & -259.86 & 361.94 \\
\hline & control & $\mathrm{PD} \geq 6 \mathrm{~mm}$ & $-344.596(*)$ & 127.969 & .027 & -655.50 & -33.70 \\
\hline & & $\mathrm{PD}<6 \mathrm{~mm}$ & -51.040 & 127.969 & .916 & -361.94 & 259.86 \\
\hline
\end{tabular}

or healthy patients [7, 27-29] as well as increased level of elastase in the course of experimentally induced gingivitis [30]. Furthermore, a reduced level of elastase in gingival crevicular fluid was observed also after surgical and non-surgical treatment [31-33], and in patients treated pharmacologically for rheumatoid arthritis [34].

Studies by Alpagot et al. [35] indicate that the level of elastase in gingival crevicular fluid - as well as the patient's age and tobacco smoking - is one of the risk factors for periodontitis in patients with diabetes.

Studies by Wells et al. [27] indicated an increased level of elastase in gingival crevicular fluid of patients with periodontitis compared to healthy individuals. Palcanis et al. [7] in their research tried to develop a diagnostic test based on measurement of the elastase concentration level in gingival crevicular fluid, which would allow to determine the risk of activity and progress of the disease in given examined sites. The authors proved that elastase concentrations were significantly higher in sites showing progression of periodontal disease (clinical attachment loss and alveolar bone loss during 6 months). The total elastase level in samples of gingival crevicular fluid was assessed by means of spectrofluorometric method. Similar results were obtained by Armitage et al. [36]. They demonstrated that examined sites where high elastase levels were observed bear a higher risk of progressive alveolar bone loss, determined by means of digital radiography. Determination of sites with a higher risk of progressive alveolar bone loss would allow to develop a standard treatment procedure for such sites, a procedure that would involve further treatment without turning to the maintenance phase in such sites, or application of additional e.g. surgical treatment methods, or application of additional chemical substances, e.g. antibiotics administered topically. Patients with such sites would also require more frequent check-up visits. Also Jin et al. [37, 38] observed significantly higher elastase levels in gingival crevicular fluid in patients with so-called refractory periodontitis compared to patients with similar progression of periodontitis who responded positively to applied treatment.

Subsequent studies on the role of elastase in destruction of periodontal tissues were based on assessing its activity in gingival crevicular fluid [31, 32, 39]. Eley and Cox [32] demonstrated that elastase activity in gingival crevicular fluid impacts the severity of periodontal disease and is associated with clinical attachment loss. Research by Jin et al. [37, 38] proved that activity of granulocytic elastase in gingival crevicular fluid is positively correlated with response to applied treatment of periodontitis. An association between histologically confirmed clinical attachment loss and increased elastase activity was demonstrated by Renvert et al. [39] in a study on beagle dogs. Chen et al. [40] tried to develop diagnostic tests for assessment of progression and progression risk of periodontal disease based on determining the activity of MMP-8 and elastase in gingival crevicular fluid in patients with chronic periodontitis. Elastase activity was established by means of fluorogenic substrate. The studies showed that both clinical parameters of periodontal tissues and total levels of examined enzymes [ng/sample] in gingival crevicular 
Table 4. Correlations of age, number of teeth, elastase and MMP-9 concentrations in the control group and the PD $\geq 6 \mathrm{~mm}$ and $\mathrm{PD}<6 \mathrm{~mm}$ groups

\begin{tabular}{|c|c|c|c|c|c|c|}
\hline Group & & & Age & No of teeth & Elastase & MMP-9 \\
\hline \multirow[t]{12}{*}{ Control } & \multirow[t]{3}{*}{ Age } & Correlation coefficient & 1 & -.137 & -.050 & .550 \\
\hline & & $p$ & & .656 & .870 & .051 \\
\hline & & $N$ & 13 & 13 & 13 & 13 \\
\hline & \multirow[t]{3}{*}{ No of teeth } & Correlation coefficient & -.137 & 1 & .259 & .019 \\
\hline & & $p$ & .656 & & .393 & .950 \\
\hline & & $N$ & 13 & 13 & 13 & 13 \\
\hline & \multirow[t]{3}{*}{ Elastase } & Correlation coefficient & -.050 & .259 & 1 & .476 \\
\hline & & $p$ & .870 & .393 & & .100 \\
\hline & & $N$ & 13 & 13 & 13 & 13 \\
\hline & \multirow[t]{3}{*}{ MMP-9 } & Correlation coefficient & .550 & .019 & .476 & 1 \\
\hline & & $p$ & .051 & .950 & .100 & \\
\hline & & $N$ & 13 & 13 & 13 & 13 \\
\hline \multirow[t]{12}{*}{$\mathrm{PD}<6$} & \multirow[t]{3}{*}{ Age } & Correlation coefficient & 1 & $-.763(* *)$ & -.211 & -.304 \\
\hline & & $p$ & & .001 & .432 & .253 \\
\hline & & $N$ & 16 & 16 & 16 & 16 \\
\hline & \multirow[t]{3}{*}{ No of teeth } & Correlation coefficient & $-.763(* *)$ & 1 & .242 & .330 \\
\hline & & $p$ & .001 & & .367 & .212 \\
\hline & & $N$ & 16 & 16 & 16 & 16 \\
\hline & \multirow[t]{3}{*}{ Elastase } & Correlation coefficient & -.211 & .242 & 1 & .201 \\
\hline & & $p$ & .432 & .367 & & .456 \\
\hline & & $N$ & 16 & 16 & 16 & 16 \\
\hline & \multirow[t]{3}{*}{ MMP-9 } & Correlation coefficient & -.304 & .330 & .201 & 1 \\
\hline & & $p$ & .253 & .212 & .456 & \\
\hline & & $N$ & 16 & 16 & 16 & 16 \\
\hline \multirow[t]{12}{*}{$\mathrm{PD} \geq 6$} & \multirow[t]{3}{*}{ Age } & Correlation coefficient & 1 & $-.624(* *)$ & -.288 & -.297 \\
\hline & & $p$ & & .010 & .280 & .265 \\
\hline & & $N$ & 16 & 16 & 16 & 16 \\
\hline & \multirow[t]{3}{*}{ No of teeth } & Correlation coefficient & $-.624(* *)$ & 1 & .491 & .411 \\
\hline & & $p$ & .010 & & .054 & .114 \\
\hline & & $N$ & 16 & 16 & 16 & 16 \\
\hline & \multirow[t]{3}{*}{ Elastase } & Correlation coefficient & -.288 & .491 & 1 & $.854(* *)$ \\
\hline & & $p$ & .280 & .054 & & .000 \\
\hline & & $N$ & 16 & 16 & 16 & 16 \\
\hline & \multirow[t]{3}{*}{ MMP-9 } & Correlation coefficient & -.297 & .411 & $.854(* *)$ & 1 \\
\hline & & $p$ & .265 & .114 & .000 & \\
\hline & & $N$ & 16 & 16 & 16 & 16 \\
\hline
\end{tabular}

${ }^{*}$ Correlation is significant at 0.01 level (two-way)

fluid are lowered as a result of non-surgical periodontal treatment. Furthermore, collagenase activity was correlated with gingival index and bleeding index. Amounts of the two examined enzymes were also correlated with each other. Figueredo and Gustafsson [41] demonstrated an increased level of active elastase in gingival crevicular fluid collected from sites indicating significant destruction of periodontal tissues. Jin et al. [42, 43] studied a relationship 
between elastase activity together with PGE2 level in gingival crevicular fluid and the presence of periopathogenic bacteria (Actinobacillus actinomycetemcomitans, Bacteroides forsythus, Porphyromonas gingivalis, Prevotella intermedia, Treponema denticola) in patients with untreated periodontitis. The authors demonstrated that topical immunological response to periopathogens is varied depending on intensity of immunological response measured by the level of elastase and PGE2 in gingival crevicular fluid.

A study by Ingman et al. [44] showed that MMP-9 is the main "gelatinase" in gingival crevicular fluid and saliva of patients with adult periodontitis (currently chronic periodontitis). Seguier et al. [45] demonstrated a direct relationship between the presence of inflammatory cells on the one hand and the level of selected metalloproteinases and collagen degradation in periodontal tissues on the other hand. Analyzing gingival biopsies of patients with periodontitis and healthy subjects, the authors found that the level of MMP-9 (among other parameters) was significantly higher in the study group than in the control group. Moreover, the level of active MMP-9 was positively correlated with elevated levels of B cells, macrophages and cytotoxic cells, and with the degree of collagen fiber degradation in the examined samples. Numerous studies indicate elevated MMP-9 levels in gingival crevicular fluid of patients with periodontitis compared to healthy subjects [46-49].

The results of quoted studies prove the significance of elastase and MMP-9 in the pathomechanism of periodontitis. In our own study, levels of both enzymes were assessed in saliva, not in situ in gingival crevicular fluid. It was assumed that mean concentrations of the studied enzymes in saliva can be resultants of concentrations in individual periodontal pockets. A significantly higher concentration of elastase in saliva in patients with chronic periodontitis compared to healthy individuals $(p<0.01)$ was observed, as well as a statistically significant difference in concentration of MMP-9 in saliva of patients with advanced periodontal disease (PD $\geq 6 \mathrm{~mm}$ ), as compared to healthy subjects $(p=0.017)$. These results are consistent with results described by Gursay et al. [50] who revealed a higher concentration of MMP-9 in saliva of periodontitis patients than in controls. These results support the argument that determining the studied enzymes in saliva can be used to develop a rapid and simple screening method for periodontal disease.

In this study, concentrations of elastase and MMP-9 in saliva in patients with chronic periodontitis and pocket depths $P D \geq 6 \mathrm{~mm}$ were compared to concentrations of elastase and MMP-9 in saliva in patients with chronic periodontitis and pocket depths $\mathrm{PD}<6 \mathrm{~mm}$. A statistically significant difference in elastase concentrations in saliva which was observed between the group with $P D \geq 6 \mathrm{~mm}$ and the group with PD $<6 \mathrm{~mm}$, and also between the group with $\mathrm{PD} \geq 6 \mathrm{~mm}$ and the control group, can indicate that periodontal pockets $\mathrm{PD} \geq 6 \mathrm{~mm}$ are the main source of the increased concentration of the enzyme in saliva. In turn, no statistically significant difference between patients with $\mathrm{PD}<6 \mathrm{~mm}$ and the control group can indicate that periodontitis diagnosis, which is based solely on clinical attachment loss, may be insufficient, and that the progression of the disease and intensity of inflammation is determined by pocket depth (PD). These results are consistent with Offenbacher et al.'s [51] proposed a new approach to the issue of division and diagnostic criteria for periodontal disease according to which patients with $\mathrm{PD}<4 \mathrm{~mm}$ are classified as healthy $(\mathrm{BOP}<10 \%)$ or as patients with gingivitis (BOP $>10 \%)$.

The lack of statistically significant differences between the levels of MMP-9 in patients with mild periodontal disease (PD $<6 \mathrm{~mm}$ ) and healthy subjects as well as between groups of patients with different degrees of severity of the disease ( $P D \geq 6 \mathrm{~mm}$ vs. $\mathrm{PD}<6 \mathrm{~mm}$ ) suggests that elastase should be considered as a more sensitive clinical indicator of the severity of the periodontal disease itself.

This assumption is also confirmed by the positive correlation between MMP-9 and elastase concentration in saliva only in patients with advanced periodontal disease (lack of correlation in the PD $<6 \mathrm{~mm}$ group and in the control group). This may mean that the studied enzymes do not affect each other in the site of inflammation, and their concentrations increase only due to the action of the same inflammatory factors that stimulate cells to their increased secretion.

Elastase and MMP-9 concentrations in saliva can be considered as biochemical indicators of severity of periodontitis.

The authors declare no conflict of interest.

\section{References}

1. Nieminen A, Asikainen S, Torkko H, et al. (1996): Value of some laboratory and clinical measurements in the treatment plan for advanced periodontitis. J Clin Periodontol 23: 572-581.

2. Socransky SS, Haffajee AD, Cugini MA, et al. (1998): Microbial complexes in subgingival plaque. J Clin Periodontol 25: 134-44.

3. Haffajjee AD, Socransky SS (2005): Microbiology of periodontal diseases: introduction. Periodontol 2000 38: 9-12.

4. Haffajee AD, Socransky SS (2006): Introduction to microbial aspects of periodontal biofilm communities, development and treatment. Periodontol 2000 42: 7-12.

5. Haffajee AD, Socransky SS, Patel MR, Song X (2008): Microbial complexes in supragingival plaque. Oral Microbiol Immunol 23: 196-205.

6. Ximénez-Fyvie LA, Haffajee AD, Socransky SS (2000): Comparison of the microbiota of supra and subgingival plaque in subjects with adult periodontitis. J Clin Periodontol 27: 722-732. 
7. Palcanis KG, Larjava IK, Wells BR, et al. (1992): Elastase as an indicator of periodontal disease progression. J Periodontol 63: 237-242.

8. Williams RC, Beck JD, Offenbacher SN (1996): The impact of new technologies to diagnose and treat periodontal disease. A look to the future. J Clin Periodontol 23: 299-305.

9. Janoff A (1985): Elastase in tissue injury. Annu Rev Med 36: 207-16.

10. Ujiie Y, Oida S, Gomi K, et al. (2007): Neutrophil elastase is involved in the initial destruction of human periodontal ligament. J Periodontal Res 42: 325-330.

11. Ujiie Y, Shimada A, Komatsu K, et al. (2008): Degradation of noncollagenous components by neutrophil elastase reduces the mechanical strength of rat periodontal ligament. J Periodontal Res 43: 22-31.

12. Figueredo CM, Gustafsson A, Asman B, Bergström K (1999): Increased release of elastase from in vitro activated peripheral neutrophils in patients with adult periodontitis. J Clin Periodontol 26: 206-211.

13. Dennison DK, Van Dyke TE (1997): The acute inflammatory response and the role of phagocytic cells in periodontal health and disease. Periodontol 2000 14: 54-78.

14. Taichman NS, Tsai CC, Baehni PC, et al. (1977): Interaction of inflammatory cells and oral microorganisms. IV. In vitro release of lysosomal constituents from polymorphonuclear leukocytes exposed to supragingival and subgingival bacterial plaque. Infect Immun 16: 1013-1023.

15. Baehni P, Tsai CC, McArthur WP, et al. (1979): Interaction of inflammatory cells and oral microorganisms. VIII. Detection of leukotoxic activity of a plaque-derived gram-negative microorganism. Infect Immun 24: 233-243.

16. Ding Y, Haapasalo M, Kerosuo E, et al. (1997): Release and activation of human neutrophil matrix metallo- and serine proteinases during phagocytosis of Fusobacterium nucleatum, Porphyromonas gingivalis and Treponema denticola. J Clin Periodontol 24: 237-248.

17. Ding Y, Uitto VJ, Haapasalo M, et al. (1996): Membrane components of Treponema denticola trigger proteinase release from human polymorphonuclear leukocytes. J Dent Res 75:1986-1993.

18. Airila-Mínsson S, Söder B, Kari K, Meurman JH (2006): Influence of combinations of bacteria on the levels of prostaglandin E2, interleukin-1beta, and granulocyte elastase in gingival crevicular fluid and on the severity of periodontal disease. J Periodontol 77: 1025-1031.

19. Page RC (1993): Periodontal therapy: prospects for the future. J Periodontol 64: 744-753.

20. Page RC (1991): The role of inflammatory mediators in pathogenesis of periodontal disease. J Periodontal Res 26: 230-242.

21. Birkedal-Hansen H, Moore WG, Bodden MK, et al. (1993): Matrix metalloproteinase: a review. Crit Rev Oral Biol Med 4: $197-250$

22. Birkedal-Hansen H (1993): Role of matrix metalloproteinases in human periodontal diseases. J Periodontol 64: 474-484.

23. Dahan M, Nawrocki B, Elkadm R, et al. (2001): Expression of matrix metalloproteinases in healthy and diseased human gingiva. J Clin Periodontol 28: 128-136.

24. Lamster IB, Ahlo JK (2007): Analysis of gingival crevicular fluid as applied to the diagnosis of oral and systemic diseases. Ann N Y Acad Sci 1098: 216-229.
25. Armitage GC (1999): Development of a classification system for periodontal diseases and conditions. Ann Periodontol 4: 1-6.

26. Navazesh M (1993): Methods for collecting saliva. Ann N Y Acad Sci 694: 72-77.

27. Wells B, Gill E, Larjava I, et al. (1990): Crevicular fluid elastase in healthy and periodontitis patients. J Dent Res 69 (Spec. Issue): 201 (Abstr. 744).

28. Zafiropoulos GG, Flores-de-Jacoby L, Todt G, et al. (1991): Gingival crevicular fluid elastase-inhibitor complex: correlation with clinical indices and subgingival flora. J Periodontal Res 26: 24-32.

29. Gustafsson A, Asman B, Bergström K, Söder PO (1992): Granulocyte elastase in gingival crevicular fluid. A possible discriminator between gingivitis and periodontitis. J Clin Periodontol 19: 535-540.

30. Giannopoulou C, Andersen E, Demeurisse C, Cimasoni G (1992): Neutrophil elastase and its inhibitors in human gingival crevicular fluid during experimental gingivitis. J Dent Res 71: 359-363.

31. Eley BM, Cox SW (1992): Cathepsin B/L-, elastase-, tryptase-, trypsin- and dipeptidyl peptidase IV-like activities in gingival crevicular fluid: a comparison of levels before and after periodontal surgery in chronic periodontitis patients. J Periodontol 63: 412-417.

32. Eley BM, Cox SW (1996): A 2-year longitudinal study of elastase in human gingival crevicular fluid and periodontal attachment loss. J Clin Periodontol 23: 681-692.

33. Jin LJ, Leung WK, Corbet EF, Söder B (2002): Relationship of changes in interleukin-8 levels and granulocyte elastase activity in gingival crevicular fluid to subgingival periodontopathogens following non-surgical periodontal therapy in subjects with chronic periodontitis. J Clin Periodontol 29: 604-614.

34. Miranda LA, Islabăo AG, Fischer RG, et al. (2007): Decreased interleukin-1beta and elastase in the gingival crevicular fluid of individuals undergoing anti-inflammatory treatment for rheumatoid arthritis. J Periodontol 78: 1612-1619.

35. Alpagot T, Silverman S, Lundergan W, et al. (2001): Crevicular fluid elastase levels in relation to periodontitis and metabolic control of diabetes. J Periodontal Res 36: 169-174.

36. Armitage GC, Jeffcoat MK, Chadwick DE, et al. (1994): Longitudinal evaluation of elastase as a marker for the progression of periodontitis. J Periodontol 65: 120-128.

37. Jin LJ, Söder PO, Asman B, Bergström K (1995): Granulocyte elastase in gingival crevicular fluid: improved monitoring of the site-specific response to treatment in patients with destructive periodontitis. J Clin Periodontol 22: 240-246.

38. Jin LJ, Söder PO, Asman B, et al. (1995): Variations in crevicular fluid elastase levels in periodontitis patients on long-term maintenance. Eur J Oral Sci 103: 84-89.

39. Renvert S, Wikström M, Mugrabi M, et al. (1998): Association of crevicular fluid elastase-like activity with histologically-confirmed attachment loss in ligature-induced periodontitis in beagle dogs. J Clin Periodontol 25: 368-374.

40. Chen HY, Cox SW, Eley BM, et al. (2000): Matrix metalloproteinase- 8 levels and elastase activities in gingival crevicular fluid from chronic adult periodontitis patients. J Clin Periodontol 27: 366-369.

41. Figueredo CM, Gustafsson A (1998): Activity and inhibition of elastase in GCF. J Clin Periodontol 25: 531-535.

42. Jin LJ, Söder PO, Leung WK, et al. (1999): Granulocyte elastase activity and PGE2 levels in gingival crevicular fluid in 
relation to the presence of subgingival periodontopathogens in subjects with untreated adult periodontitis. J Clin Periodontol 26: 531-540.

43. Jin L, Söder B, Corbet EF (2000): Interleukin-8 and granulocyte elastase in gingival crevicular fluid in relation to periodontopathogens in untreated adult periodontitis. J Periodontol 71: 929-939.

44. Ingman T, Tervahartiala T, Ding Y, et al. (1996): Matrix metalloproteinases and their inhibitors in gingival crevicular fluid and saliva of periodontitis patients. J Clin Periodontol 23: 1127-1132.

45. Séguier S, Gogly B, Bodineau A, et al. (2001): Is collagen breakdown during periodontitis linked to inflammatory cells and expression of matrix metalloproteinases and tissue inhibitors of metalloproteinases in human gingival tissue. J Periodontol 72: 1398-1406.

46. Rai B, Kaur J, Jain R, Anand SC (2010): Levels of gingival crevicular metalloproteinases- 8 and -9 in periodontitis. Saudi Dent J 22: 129-131.

47. Rai B, Kharb S, Jain R, Anand SC (2008): Biomarkers of periodontitis in oral fluids. J Oral Sci 50: 53-56.

48. Beklen A, Tüter G, Sorsa T, et al. (2006): Gingival tissue and crevicular fluid co-operation in adult periodontitis. J Dent Res 85: 59-63.

49. Marcaccini AM, Meschiari CA, Zuardi LR, et al. (2010): Gingival crevicular fluid levels of MMP-8, MMP-9, TIMP-2, and MPO decrease after periodontal therapy. J Clin Periodontol 37: 180-190.

50. Gursoy UK, Könönen E, Huumonen S, et al. (2013): Salivary type I collagen degradation end-products and related matrix metalloproteinases in periodontitis. J Clin Periodontol 40: 18-25.

51. Offenbacher S, Barros SP, Beck JD (2008): Rethinking periodontal inflammation. J Periodontol 79 (8 Suppl): 1577-1584. 